\title{
Adolescent health - A call for help and support
}

\author{
P S de Silva ${ }^{1}$ \\ Sri Lanka Journal of Child Health, 2003; 32: 6-10
}

(Key words: adolescent health)

Traditionally, when we want to assess the health of any population, we tend to use mortality factors, such as the number of deaths per thousand, prevalence of certain diseases in the society etc, as metrics. This is quite normal, as addressing of mortality issues should get first priority in any health care program. However, the value of a health care program, which does not sufficiently address morbidity factors, is questionable as any unresolved morbidity issues are likely to manifest as mortality factors, sooner rather than later. This gradually became quite obvious to me, as I got more and more involved in my work with thalassaemia patients, as well as their parents, caretakers and community groups. I was fortunate that the work I did to control thalassaemia brought about significant changes in the mortality figures, which in turn, gave me the opportunity to address wider social issues as they were getting into the adolescent age group. It was at this stage, that I realised, how little importance we pay to adolescent health issues. Parents instinctively know the vulnerability of infants, toddlers and very young children, and as a result, health needs of children of this age group are rarely neglected. Adults generally tend to look after themselves and the elderly are, to some extent, well looked after by their children. But because of the very fact that adolescents and young adults generally tend to be in good health, society tends to pay less attention to the physical and mental health issues of this group of people.

We hardly stop to ask about the health of adolescents and young adults; they are young, therefore their health must be OK. We tend to have lost touch with their problems. These are considered non significant, trivial and we somehow expect them to sort out these problems themselves. Sometimes we even do not know what their problems are - so much so that we go into a state of shock, embarrassment and

\footnotetext{
${ }^{1}$ Consultant Paediatrician, Colombo South Teaching Hospital.

* Address given on Induction as President, SLCP, November 2002.
}

helplessness to be of assistance to these people. Let me give you an example;

One of my senior colleagues, with almost 30 years experience in paediatrics, assisted in a clinic conducted at a border village. After completing his work with the paediatric patients that day, he thought of assisting the physicians with the adult patients. On this particular day, the very first patient who came to consult him was a boy aged 16 years. "What is your problem?" asked my colleague in a very relaxed manner. Prompt came the reply from the boy, "Sir, my tool is not firing"! My colleague was taken aback and, for a moment, was lost for words. He was not sure how to respond to his young patient's problem. He then decided to admit to his patient that he has no experience in treating such conditions and referred the patient to one of the other physicians.

I found this story amusing too. However, this little anecdote illustrates what I was trying to tell you earlier. We tend to be surprised and helpless when adolescents confront us with their problems, don't we? I can assure you, this is not a single isolated incident and I am sure most of you must have heard many similar stories.

The adolescents, who according to a WHO definition, is the group of people in the age bracket of 10-18 years, comprise 1.5 billion in the world population or in other words, $30 \%$ of the global population. In Sri Lanka, the adolescent population is 1.8 million or roughly, $12 \%$ of the total population.

Pre-teen and teenage years can be some of the most exciting times in life and also times of enormous change. As children become adults, they begin experiencing changes in the way they look, the way they feel, and the way they think. Those of you here who have, or, had children of this age group I am sure, can appreciate the significance of the problems adolescents generally tend to go through. Just cast your mind back to your own adolescent period. Is there a single person in this audience, who can claim, that he, or she went through the adolescent period 
without any physical and mental turmoil of some form or another?

Culturally, we tend to ignore most of the problems faced by adolescents. Somehow, it is felt that this is a topic that should not be discussed openly or even discussed at all. We always hope that these problems will fade away eventually without leaving any scars on our mental and physical well-being.

Recently, the Health Education Bureau ran a campaign to educate adolescents about their normal physiological developments. At the end of one of these programs, the official requested the young audience to ask any questions with the assurance of maintaining anonymity. The students, encouraged by this assurance, wrote down the questions on pieces of paper and forwarded them to the speaker. Let me share some of the questions raised by these kids with you - please note, that these are the exact words used by the students.

- What is a 'hymen'?

- What happens to the hymen during sexual intercourse?

- Is it true that girls who take part in sports have ruptured hymens?

- How long will a sperm live after entering the female genital tract?

- What is a condom?

- My Dick is about 7 inches. Is it normal?

- What is the reason for occurrence of pimples?

- Why do pimples appear at each menstrual period?

- Is there an increased incidence of asthma and phlegm if one is born prematurely?

- What should be done if there is no menstruation for 4 years after the first period?

- Is oestrogen hormone the same as progesterone?

- How many days after the periods are the ova formed? How many ova are formed each month?

- How could one find a girl who is not infected with any sexually transmitted diseases? Are there any externally noticeable signs?

- Does daily masturbation have any ill effects on health? (loss of energy, weakness of the knees, sleepiness, loss of weight)

It is worthwhile noting that they are very worried about the physical and physiological changes that take place during this period but our social environment is not conducive for them to freely question the above issues
When I first saw these responses, my immediate reaction was one of surprise, slight embarrassment and strong judgment of the individual responses. No doubt most of you here would share similar feelings deep down within you. Although, as clinicians, we are taught and made to understand the physiological aspects of adolescent development, yet somehow, the feelings stirred up when confronted with such questions tend to shatter our own rational knowledge base and pathological understanding of human growth. I believe that this is a direct result of the social cultural values we place on issues related to adolescent development.

It is not hard to understand the impact of the responses adolescents tend to receive from adults in the general society. In most societies, especially in developing countries like ours, the physiological issues about adolescence are rarely discussed openly and even thinking about such issues is considered taboo.

When children enter puberty, they are often shy and uncomfortable with the changes taking place in their bodies. As they grow, they become more prone to acne, menstrual problems, fatigue, pubertal concerns, weight control issues (eating disorders, obesity) and behavioural issues.

An adolescent who has very little knowledge, or control of the changes that are occurring in her/his body, goes through these changes with extreme anxiety and perplexity, mostly in silence. As the society at large generally tend to ignore these concerns as mere problems, the only option the adolescent has, is to carry this burden by himself or herself, rely on support from his or her peers, or turn to social vices such as smoking, drinking and drug abuse. Those who can get no consolation from any of these outlets will unfortunately, resort to committing suicide, the only course of action open for them rather than having to cope with this stressful situation which is largely ignored by rest of the society.

Some of you may be surprised to know that Sri Lanka tops the list when it came to youth suicide rate. Also that $2 \%$ of population in prison and detention homes are adolescents. While other socio-economic factors may also influence these unfortunate events, by and large they tend to act as catalysts while the root cause can still be traced to unmanaged or poorly managed adolescence.

Even in this country, some school principals have indicated that there is much reproductive health related behaviour among school adolescents such as 
adolescent love affairs, elopement, premarital sex, premarital pregnancy, homosexual relationships, patronising prostitutes, rape, abortion, suicide and an addiction to smoking and drugs.

Surveys and focus group discussions with both adults and adolescents have revealed the current lack of accurate information about sexuality. This lack of information is attributed to prevailing cultural values. There is great debate as to how, where, and who, should give them information. Some teachers are embarrassed about teaching reproductive health and tend to skim through the subject matter. The teachers even go the extent of telling the students not to ask questions and equally embarrassed students, too, refrain from asking questions to clarify their doubts. This is clearly illustrated by the questions I showed you earlier on.

Birth registration data in Sri Lanka indicate that 7\% of all live births in the year 2000 were attributed to girls aged 15-18 years. The actual number of pregnancies among this age group is not known because data on abortion and miscarriage are lacking; however, a study undertaken two years ago showed that about one fifth of all abortions occurred among adolescents. It is, of course, not hard for one to guess the number of illegal abortions performed in this country and elsewhere and the risks associated with such procedures to the physical and mental well being of the adolescents.

In response to this social problem and its significant impact on the health of an individual in subsequent years, some countries have special clinics for adolescents. The adolescent medicine specialists in these clinics help young adults understand these changes and learn how to develop a sense of responsibility for their own health care.

These clinics tend to differ from the clinics we are normally familiar with. The main focus has been to create multi-disciplinary and multi-services clinics involving paediatricians, adult physicians, child and adolescent psychologist, obstetricians and counselors etc. Adolescent problems can be triggered off by vastly different causes such as physiological, psychosomatic, social and economical etc. As such, having various services under a single roof enables the clinic to provide a holistic approach to resolving adolescent problems.

To give you an example, the adolescent clinic at University of Michigan, Chicago has a clearly defined process for handling new cases. The visit begins with a clinical interview with an adolescent by introducing the clinician to the teenager and his/her parent. This gives the clinician the opportunity to record a broad outline of the problem and the environmental factors surrounding the case. Following this process a physical examination of the patient is undertaken maintaining the privacy of the adolescent. Once this process is completed, a psychological review surrounding the case is undertaken again without the presence of the parents. Details such as home environment, education, employment, entertainment, eating, nutrition, psychological state of the patient, drugs, sexuality etc are noted down. At the end of this process the patient is provided counseling. During all these stages, the clinic attempts to maintain a high degree of confidentiality and to win the confidence of the young patient.

In Sri Lanka depending on their age, adolescents generally get sent to an adult ward where they are invariably treated as 'kids' or little children. And, more often than not, they are discharged as soon as the symptoms are treated. Their privacy is one of the last things the staff would worry about, although for these adolescents, this would be one of the most important factors if they were to confide in the clinician.

It goes without saying that privacy and confidentiality are the key factors that will determine the success or failure of such clinics. Sadly, most adults do not possess the ability to communicate effectively with adolescents and as a consequence it builds up mistrust and suspicion between them. Adolescents, caught up in this difficult situation, turn to peer groups and further isolate themselves from adults. The trust and confidence between these two groups can only be restored by assuring a high level of privacy and confidentiality for the adolescent patients who may visit such clinics.

I always thought that adolescents would hardly like to discuss matters relating to puberty and their health with clinicians and they almost all the time turned to their peers for advice and guidance. Contrary to my belief, a survey undertaken among 150 Advanced Level students shows that a significant number of them did approach the clinicians to consult on matters relating to their health as can be seen from the following chart.

Table 1

Sources of advice on adolescent health matters

\begin{tabular}{|l|c|}
\hline Parents & $60 \%$ \\
\hline Teachers & $10 \%$ \\
\hline Friends & $45 \%$ \\
\hline Doctors & $40 \%$ \\
\hline
\end{tabular}


It is gratifying to see that $60 \%$ of the adolescents surveyed still approach their parents for advice. More interestingly, $98 \%$ of them expressed the need to have a clinic where they could freely go to consult a clinician on matters relating to their physical and mental health.

When the admissions to Colombo South Teaching Hospital were analyzed, we realized that adolescent admissions constituted $12.2 \%$ of the total hospital admissions. Of these $68 \%$ of them were discharged within less than 48 hours of admission

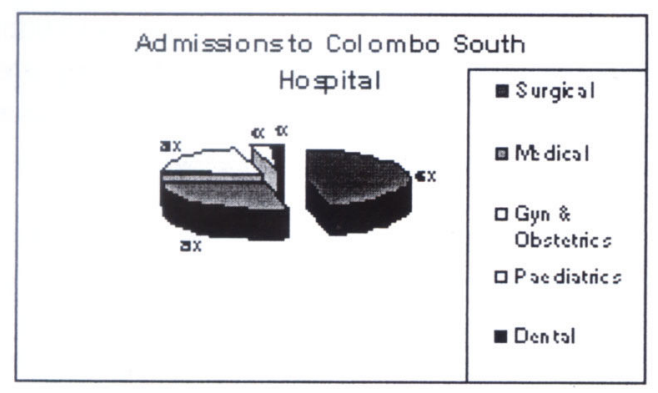

Analysis of the OPD attendance shows that 9\% of them were adolescents seeking treatment. This shows that adolescents do come to hospital seeking help. But with our busy schedule in the hospital are we giving an adequate hearing to them? We have discharged almost $70 \%$ of them the following day.

The adolescents, representing $3.5 \%$ paediatric admissions, except for few asthmatics, complained of abdominal pain, chest pain and headache. In most cases blood counts were taken and in some cases even echocardiograms, X-rays and ultra sound examinations were conducted. However, despite all the investigative analysis undertaken, most of them were discharged without any definitive diagnosis being made by us.

It is interesting to note that one such patient, a 10 year old girl, came to us for the 3rd time with recurrent abdominal pain; we could not find any pathological reason and as such referred her to the Adolescent Psychiatrist in our hospital. After about 45 minutes interview it was revealed that her father regularly abused the mother and for this little girl, getting admitted to the hospital was the only way of preventing her mother being assaulted.

Thus, most of our adolescents were having psychosomatic disorders. I was told by my psychiatric colleagues that getting the adolescent to draw is an easy way of getting to know their inert problems
In Sri Lanka, various people and organisations have already realized the importance of providing services accessible to our adolescents. These include services provided by the Health Education Bureau, Family Health Bureau, FPA, STD campaign, UNDFPA. While most of these organizations provide a commendable level of service, despite budgetary constraints, what appear to be lacking are clinical services. In addition to this, steps must be taken to co-ordinate the efforts of these multiple organisations. The clinical services play a pivotal role in resolving adolescent issues and as such should take on the co-ordination role for services offered to adolescents.

Distinguished guests, ladies and gentlemen, there is a large body of information out there highlighting the significance and the enormity of the problem of addressing adolescent problems of our society. As clinicians, parents, relatives and ordinary citizens in the society, we all intuitively know the gravity of this problem; yet, so far, most of us have been too busy with our day to day work helping to resolve seemingly more important issues.

However, it is my firm belief that unless we start working towards resolving this problem today, we will not be able to cope with the tidal wave of even more burning issues that will come crashing down on us tomorrow. The ravages of the war, collapsing economy, rising unemployment, disintegration of social fabric and exposure to globalisation are all contributory factors that put enormous pressure on the adolescent life in Sri Lanka today.

As paediatricians, I believe that we must take the initiative to set up effective communications channels with other agencies involved in providing assistance to adolescents and work together with these agencies rather than work in isolation. As you know, complex problems require solutions designed by a multidisciplinary team for, them to be effective.

Towards this end, I am happy to inform you, that we have commenced preliminary work in establishing an adolescent clinic in the Colombo South Hospital. So far, we have consulted the community groups, UNICEF, counselors, psychologists, social workers and most importantly, a group of adolescents in identifying the priority needs and determining the services that would be required to meet those needs.

It is my hope that during my tenure as your President, our work will trigger similar projects around the country. We hope to hold seminars and workshops to develop better strategies and solutions for achieving optimum results. 
In conclusion, let me share a short story with you. She is Kanthi, a 14 year old carrying her baby. She went through a caesarian section to deliver the baby. She herself is one of three sibs from Anuradhapura; her father was an alcoholic and had been abusing her mother since the days she could remember. Father finally left home, taking the brother, to get married to another woman. The elder sister was given in marriage. Kanthi was given to a house in Kurunegala as a domestic to earn some money. Kanthi was very happy at the new home and was treated very well. But one weekend she was left alone in the house with the 55 year old gardener. He raped her and left the house. By 3 months it was quite obvious that she was showing signs of pregnancy. She was sent back to the village. Mother, unable to face the embarrassment, with the help of her son in law, managed to put her to a home in Moratuwa where she was looked after throughout her pregnancy. Kanthi loves the baby and had ideas of taking the baby to the village. I wonder whether her dreams will come true.

Ladies and gentlemen, Kanthi was in fact, one of those lucky few who managed to get through a traumatic period although the outcome was not the ideal by any standards. Just think about the thousands of others who could not even get as far as Kanthi did. Most would have committed suicide, resorted to alcohol and drug abuse or even ended up in mental asylums. But timely action by us now, would help save thousands more ending up with the same fate.

As you know this is a mammoth task but as the famous saying goes, 'A journey of a thousand miles starts with one single step'; it is a task that cannot be undertaken by a single individual or a single organisation alone - it is a task that requires the support of every individual in the society and every organisation in this country.
Clearly, eradication of every single adolescent problem in our society is an unattainable goal. However, my vision is to make adolescence as trouble free as possible for the young people in Sri Lanka.

Adolescents are like butterflies. They go through a transition period that is full of potential, yet fragile. They need nurturing and care and a safe and supportive environment to grow and develop. They are the future of every society and also a great resource of the nation.

As your President, I would like to ask for your assistance, support and encouragement in every possible way to realise this vision in the coming year. Year 2003 is being declared by the World Health Organization as the year for Adolescents. Therefore let us begin by improving our skills to deal with adolescents and establish adolescent friendly services in our institutions.

Let me take this opportunity to thank, Profs Colvin Gunaratne, Kumudu Wijewardena and Dr. H. Yakandawela from UNICEF for sharing their knowledge and experience with me. The Director of the hospital Dr. U Goonewardena, Director Youth and elderly from the Ministry of Health Dr. Deepthi Perera for giving encouragement and support for establishing the Adolescent Clinic at T.H. Colombo South. To all my house officers who helped me in collecting and analysing the data. 
